\title{
Perceptions about mental illness among general practitioners
}

\author{
Ma Carmen Castillejos Anguiano ${ }^{1 *} \mathbb{D}$, Antonio Bordallo Aragón², David Aguilera Fernández² \\ and Berta Moreno Küstner ${ }^{1,3}$
}

\begin{abstract}
Background: General practitioners (GPs) play an important role in the physical care of patients with severe mental illness, so our aim was to analyse the relationships between GPs' sociodemographic status and worked-related variables and their perceptions about mental illness.

Methods: A descriptive, cross-sectional study was conducted in the Clinical Management Unit of Mental Health (CMU-MH) of the Regional Hospital of Malaga (Spain). The eligible population comprised all GPs working in the 13 primary care centres (PCCs) in the hospital's catchment area during the study period. GPs were interviewed to collect data on their attitudes to and knowledge of mental illness, psychiatry and the local mental health team, as well as their sociodemographic status, professional qualifications and experience. Bivariate analysis was carried out.

Results: 145 GPs answered the questionnaire (77\%). ANOVA revealed that most of the PCCs with the best relationship with their mental health team and best attitude to mental illness were in the Central Community Mental Health Unit, which operated a collaborative model of care.

Conclusions: These results indicated that GPs who worked more closely with their specialist mental health team had a better perception of their relationship with the mental health centre and less stigmatisation in regard to mental illness.
\end{abstract}

Keywords: Primary care, Schizophrenia, Stigma, Collaborative model

\section{Background}

It is widely known that patients with mental illness experience discrimination and stigmatisation [1-3]. There has been a lot of research into self-stigmatisation by individuals with mental illness $[4,5]$, which is often due to societal stigmatisation of mental illness $[6,7]$.

One would expect health professionals to have a more positive attitude to mental illness and the mentally ill because of their professional knowledge, but several studies have shown that this is not the case $[8,9]$. A recent systematic review concluded that older general practitioners (GPs) had a more negative attitude to patients with schizophrenia [10]. It has been shown that GPs'

\footnotetext{
*Correspondence: mccasang@gmail.com

${ }^{1}$ Andalusian Group of Psychosocial Research (GAP), Department of Personality, Assessment and Psychological Treatment, University of Malaga, Campus Teatinos, Malaga, Spain

Full list of author information is available at the end of the article
}

stigmatisation of patients with mental illness depends on their level of experience of such patients, so that the more experience they have, the less stigmatisation they exhibit [11]. Comparisons of the attitudes of different categories of health professional have shown that GPs stigmatise mental illness more than psychiatrists do [12-14].

Health professionals' perception of mental illness and their attitude to the mentally ill could influence their decisions in daily practice [15]. Moreover, health professionals' negative attitude is detected by patients [16] and may be a factor in the low rate of engagement of patients with serious mental illness with healthcare services [14].

A recent study carried out in the United States showed that GPs faced significant barriers to providing good care to patients with mental illness: lack of time and resources and lack of confidence $[11,17]$.

GPs play an important role in the care of patients with severe mental illness (SMI) because these patients have 
higher rates of mortality and morbidity from physical health problems than the general population [18-20] and because GPs are the main point of entry into the Spanish health system. We therefore aimed to analyse the relationships between GPs' sociodemographic status, work-related variables and their perceptions regarding mental illness. These perceptions will be defined as the level of satisfaction of GPs with their relationship with the community mental health centre, their erroneous beliefs, stigmatisation and attitudes regarding mental illness and their perception of their level of training in mental health, schizophrenia and other psychotic disorders..

\section{Material and methods}

This was a descriptive, cross-sectional study.

\section{Study area and temporal scope}

The study was carried out in the CMU-MH of the Regional Hospital of Malaga, with two Community Mental Health Units (CMHUs), Central and Northern, which together covered a population of 315,159 . The Central CMHU included 6 PCCs: Alameda-Perchel, Victoria, Limonar, El Palo, Colmenar and el Rincón de la Victoria; and the Northern CMHU included 7 PCCs: Trinidad, Nueva Malaga, Miraflores, Palma-Pamilla, Ciudad-Jardín, Capuchinos and Carlinda.

The study information was collected from January 1, 2008 to July 1, 2011.

\section{Eligible population and sample}

The eligible population comprised 188 GPs working in the 13 PCCs in the catchment area of CMU-MH of the Malaga Regional Hospital during the study period.

\section{Questionnaire and study variables}

We used the Primary Care Physicians and Mental Health Questionnaire (MAPSAM-14), which had been validated by the research team [21], to assess perceptions of GPs towards mental health.

So our dependent variables were scores on the three MAPSAM-14 scales, (1) Relationship: level of satisfaction of GPs with their relationship with the community mental health centre (range 7-15; higher scores indicated greater satisfaction with the relationship); (2) Beliefs: this touched upon erroneous beliefs, stigmas and attitudes regarding mental illness (range 5-12; higher scores indicate more erroneous beliefs and greater stigmatisation); (3) Training: the GPs' perception of their level of training in mental health, schizophrenia and other psychotic disorders (range 5-15; higher scores indicate greater perceived adequacy of training).

The independent variables were age; gender; years in the current place of work ( $\leq 3$ years; $>3$ years); specialisation training as a GP (yes/no); accredited training as a tutors (yes/no); to have any residential training students (yes/no); size of patient list $(\leq 1500 ;>1500)$, PCC affiliation (Alameda-Perchel, Victoria, Limonar, El Palo, Colmenar, el Rincón de la Victoria, Trinidad, Nueva Malaga, Miraflores, Palma-Pamilla, Ciudad-Jardín, Capuchinos and Carlinda.). These variables were obtained using a self-report questionnaire.

\section{Data analysis}

Bivariate analysis of the relationships between the sociodemographic and work-related variables and the MAPSAM-14 variables (Relationship, Beliefs and Training) was carried out. For the independent dichotomous qualitative variables a Student's t-test was used. And for the independent qualitative polytomous variables, analysis of variance (ANOVA) was used. Differences were considered significant at $p<0.05$.

The statistical program SPSS statistics 22 was used for the construction of the database, the descriptive analyses and for the bivariate analysis.

\section{Results}

There were 188 GPs serving the catchment area of Malaga regional hospital, of whom 145 answered the questionnaire, a response rate of $77 \%$.

The mean age of the sample was 50.5 (95\% CI 49.551.5; range 35-63) and the median age was 51.5 years (range $35-6$ and $64.7 \%$ was male. Mean professional experience was 7.2 years (95\% CI 5.3-9.1; range 0-30). Forty-four percent of participating GPs had hospital resident training, $64.7 \%$ were not accredited training tutors and $60.8 \%$ had not led a hospital doctor team in the last 3 years. The mean patient list size was 1608 (95\% CI 1538.2-1678.8; median $=1500$; range 900-2500).

Turning to the MAPSAM-14 variables, the mean scores were as follows: the level of satisfaction of GPs with their relationship with the community mental health centre [Relationship] was $\mathrm{M}=12.51$ (95\% CI 12.16-12.87), with the highest level of satisfaction being $M=15$; the dimension [Beliefs] that touched upon erroneous beliefs, stigmas and attitudes regarding mental illness was $\mathrm{M}=8.04$ (95\% CI 7.79-8.28), with the highest level of stigmatisation being $\mathrm{M}=12$; and the dimension [Training] that measured the perception of GPs of their level of training in mental health, schizophrenia and other psychotic disorders was $\mathrm{M}=8.61$ (95\% CI 6.43-10.80), with the highest rate being $M=15$, which indicates greater perceived adequacy of training.

As result of the bivariate analysis, the only dichotomous variable related to the level of satisfaction of GPs with their relationship with the community mental health centre was size of patient list: having a list of more than 
1500 patients was associated with a better level of satisfaction with their relationship with the community mental health centre $(p=0.034)$ (Table 1$)$.

The ANOVA revealed differences between PCCs GPs affiliations with respect to the level of satisfaction with their relationship with the community mental health centre and beliefs about mental illness (both $p s<0.001$ ).
The PCCs where GPs' perception of the relationship with the local mental health team was best were El Rincón de la Victoria and El Palo. The PCCs where GPs had less stigmatisation regarding mental illness were Victoria, El Palo, El Rincón de la Victoria, Limonar, Alameda-Perchel and Nueva Malaga (Table 2); all these PCCs were linked with the Central CMHU except for Nueva Malaga.

Table 1 Student's t-tests for GPs' sociodemographic status, professional experience and qualifications

\begin{tabular}{|c|c|c|c|c|c|c|c|}
\hline & \multirow[t]{2}{*}{$\mathbf{t}$} & \multirow[t]{2}{*}{ df } & \multirow[t]{2}{*}{$p$ value } & \multirow[t]{2}{*}{ Mean differences } & \multirow{2}{*}{$\begin{array}{l}\text { Standard error } \\
\text { differences }\end{array}$} & \multicolumn{2}{|c|}{$95 \%$ confidence interval } \\
\hline & & & & & & Lower limit & Upper limit \\
\hline \multicolumn{8}{|l|}{ D1: Relationship } \\
\hline Gender & -1.739 & 140 & 0.084 & -0.626 & 0.360 & -1.338 & 0.086 \\
\hline Years in the current place of work & -0.074 & 91 & 0.941 & -0.033 & 0.443 & -0.912 & 0.846 \\
\hline Specialisation training as a GP & 0.882 & 137 & 0.379 & 0.324 & 0.368 & -0.403 & 1.501 \\
\hline Accredited training as a tutors & 0.515 & 140 & 0.607 & 0.194 & 0.377 & -0.552 & 0.941 \\
\hline To have any residential training students & 0.589 & 140 & 0.557 & 0.221 & 0.374 & -0.519 & 0.960 \\
\hline Size of patient list & -2.139 & 140 & 0.034 & -0.780 & 0.365 & -1.500 & -0.059 \\
\hline \multicolumn{8}{|l|}{ D2: Beliefs } \\
\hline Gender & 0.882 & 140 & 0.379 & 0.224 & 0.254 & -0.278 & 726 \\
\hline Years in the current place of work & 1.558 & 91 & 0.123 & 0.504 & 0.323 & -0.139 & 1.146 \\
\hline Specialisation training as a GP & -1.462 & 137 & 0.146 & -0.372 & 0.255 & -0.876 & 0.131 \\
\hline Accredited training as a tutors & -1.264 & 140 & 0.208 & -0.332 & 0.263 & -0.852 & 0.187 \\
\hline To have any residential training students & -1.736 & 140 & 0.085 & -0.450 & 0.259 & -0.963 & 0.063 \\
\hline Size of patient list & 1.391 & 140 & 0.166 & 0.358 & 0.257 & -0.151 & 0.867 \\
\hline \multicolumn{8}{|l|}{ D3:Training } \\
\hline Gender & 0.585 & 143 & 0.559 & 1.307 & 2.232 & -3.105 & 5.718 \\
\hline Years in the current place of work & -1.419 & 93 & 0.159 & -3.896 & 2.746 & -9.348 & 1.557 \\
\hline Specialisation training as a GP & -0.413 & 140 & 0.680 & -0.936 & 2.265 & -5.414 & 3.543 \\
\hline Accredited training as a tutors & -1.285 & 143 & 0.201 & -2.982 & 2.321 & -7.570 & 1.606 \\
\hline To have any residential training students & -1.109 & 142 & 0.269 & -2.115 & 1.907 & -5.885 & 1.654 \\
\hline Size of patient list & 1.635 & 143 & 0.107 & 4.466 & 2.731 & -1.002 & 9.933 \\
\hline
\end{tabular}

Table 2 ANOVA of primary care centre differences in relationship with the local mental health team, beliefs about mental illness and perceptions of the adequacy of training in mental health

\begin{tabular}{lccc}
\hline & Sum of squares & df & Root mean square \\
\hline D1: Relationship & & 12 & \\
Between groups & 186.835 & 129 & 15.570 \\
Within groups & 460.637 & 141 & 3.571 \\
Total & 647.472 & & \\
D2: Beliefs & & 12 & 7.548 \\
Between groups & 90.570 & 129 & 1.754 \\
Within groups & 226.254 & 141 & \\
Total & 316.824 & 12 & 163.148 \\
D3: Training & & 132 & 178.550 \\
Between groups & 1957.781 & 144 & 0.001 \\
Within groups & $23,568.591$ & & 0.535 \\
Total & $25,526.372$ & & \\
\hline
\end{tabular}




\section{Discussion}

This study analysed the relationships between the three MAPSAM-14 dimensions (level of satisfaction of GPs with their relationship with the community mental health centre, their erroneous beliefs, stigmatisation and attitudes regarding mental illness and their perception of their level of training in mental health, schizophrenia and other psychotic disorder) and GPs' age, gender and professional experience and qualifications.

The only variable associated with GPs' relationship with their local mental health teams was the size of their patient list; those GPs with a longer list (>1500) perceived that they had a better relationship with the mental health team, perhaps because they had more contact with it and, therefore, this fact could be valued by the GPs as a more effective communication and relationship.

None of the sociodemographic or work-related variables was associated with GPs' beliefs about mental illness, which conflicts with the results of Rojas-Vistorte et al. and Lam et al. [10, 22]. They found that GPs who stigmatised mental illness tended to be more experienced, female, work at hospital level and not to have relatives or friends affected by mental disorders.

Finally, GPs perception of the adequacy of their training in mental health problems was not associated with any of the sociodemographic or work-related variables.

Our most important finding, however, was that GPs' perception of their relationship with the local mental health team and their beliefs about mental illness varied according to their PCC affiliation. The GPs which reported the best relationship with the community mental health centre were all working in PCCs located in the catchment area of the Central CMHU. Similarly, GPs affiliated to the six teams with the lowest Belief scores (i.e. less erroneous beliefs, stigmas and attitudes regarding mental illness) all but one (Nueva Malaga) belonged to the Central CMHU catchment area. At the time of the study the Central CMHU had been working collaboratively with GPs for over 15 years, whereas the Northern CMHU had more traditional working relationships with GPs. This suggests that collaborative working improves communication and relationships between specialist mental health teams and GPs. It may also help to minimise misunderstanding of mental illness amongst GPs, because greater contact between GPs and mental health teams may increase GPs' knowledge and understanding of mental illness; this relationship between contact with mental health services and knowledge of mental illness has in fact been observed in the general population [23]. Probably these aspects favour better care for patients with mental illness from Primary Care. At present, new, more collaborative relationship between primary and secondary care are being introduced in order to provide patients with mental illness with better, more holistic care [24]. Collaborative ways of working have been shown to improve the care of patients with severe mental illness [25-27]. A study carried out in a rural area showed that patients preferred services where there was an emphasis on collaboration between primary care and specialist mental health services [28].

\section{Strengths and limitations}

- This study analysed multiple associations between GPs' characteristics and their attitude to and knowledge of mental illness and their relationship with their local mental health team.

- The study was carried out in a clinical mental health management unit with considerable experience of working collaboratively with primary care practitioners; the unit concerned is one of the pioneers in this area in Andalucia.

- The study was carried out in a wide catchment area, including participants from 13 primary care centres. However, we could not consider differences between rural and urban PCCs as we had only one small PCC in a rural area.

- For unknown reasons not all GPs in the study area participated, and in some cases, the number of GPs per centre was very low. However, in general, the participation rate was high.

- We should be aware that there could be a bias concerning GPs who answer the questionnaire as they could have a better perception of their level of training in mental health or a more positive attitude towards mental illness.

- We did not analyse nursing staff, although they are very involved in the treatment of patients with mental illness.

\section{Conclusion}

In this study we analysed relationships between multiple GP characteristics and GPs' attitudes to mental illness, but our main finding was that GPs working at PCCs in the catchment area of Central CMHU, which had much greater experience of working collaboratively with GPs than the other CMHU in the study, perceived themselves to have a better relationship with their local mental health centre and less stigmatisation regarding mental illness.

\section{Relevance for clinical practice}

Due to the results obtained, and given the important role that GPs play in caring for the physical health of patients with severe mental illness, we strongly recommend that 
more collaborative relationships between primary care teams and specialist mental health teams are widely implemented, in order to improve overall healthcare for people with mental illness.

\section{Authors' contributions}

MCCA analysed the data and wrote the final manuscript. ABA collected the data, analysed the data and wrote the preliminary draft. DAF contributed to carried out the study and analysed the data. BMK designed the study, analysed the data and revised the manuscript. All authors are in agreement with the manuscript. All authors read and approved the final manuscript.

\section{Author details}

${ }^{1}$ Andalusian Group of Psychosocial Research (GAP), Department of Personality, Assessment and Psychological Treatment, University of Malaga, Campus Teatinos, Malaga, Spain. ${ }^{2}$ Clinical Management Unit of Mental Health of the Regional Hospital of Malaga, Andalusian Health Service, Avda del Hospital Civil S/N, Paseo Limonar, Malaga, Spain. ${ }^{3}$ Biomedical Research Institute of Malaga (IBIMA), Malaga, Spain.

\section{Competing interests}

The authors declare that they have no competing interests.

\section{Availability of data and materials}

The data that support the findings of this study are available from Berta Moreno Küstner but restrictions apply to the availability of these data, which were used under license for the current study, and so are not publicly available. Data are however available from the authors upon reasonable request and with permission of Berta Moreno Küstner.

\section{Consent to participate}

Not applicable.

\section{Ethics approval and consent to participate}

The study was approved by the Health Research Ethics Committee of the Health District of Malaga.

\section{Funding}

This work was supported by Consejería de Economía, Innovación, Ciencia y Empleo, Junta de Andalucía (Award Number: P10-CTS-5862, CTS-945) and Fundación Progreso y Salud (Award Number: PI-0193/2014).

\section{Publisher's Note}

Springer Nature remains neutral with regard to jurisdictional claims in published maps and institutional affiliations.

Received: 29 January 2019 Accepted: 10 April 2019

Published online: 13 April 2019

\section{References}

1. Ando S, Yamaguchi S, Aoki Y, Thornicroft G. Review of mental-healthrelated stigma in Japan. Psychiatry Clin Neurosci. 2013;67:471-82.

2. Stier A, Hinshaw S. Explicit and implicit stigma against individuals with mental illness. Aust Psychol. 2007;42:106-17.

3. Thornicroft G, Brohan E, Rose D, Sartorius N, Leese M. Global pattern of experienced and anticipated discrimination against people with schizophrenia: a cross-sectional survey. Lancet. 2009;373:408-15.

4. Girma E, Tesfaye M, Froeschl G, Möller-Leimkühler AM, Dehning S, Müller N. Facility based cross-sectional study of self stigma among people with mental illness: towards patient empowerment approach. Int J Ment Health Syst. 2013;7:21.

5. Tang I-C, Wu H-C. Quality of Life and Self-Stigma in Individuals with Schizophrenia. Psychiatr Q. 2012;83:497-507.

6. Evans-Lacko S, Brohan E, Mojtabai R, Thornicroft G. Association between public views of mental illness and self-stigma among individuals with mental illness in 14 European countries. Psychol Med. 2012;42:1741-52.
7. Hanafiah AN, Bortel TV. A qualitative exploration of the perspectives of mental health professionals on stigma and discrimination of mental illness in Malaysia. Int J Ment Health Syst. 2015;9:10.

8. Li J, Li J, Thornicroft G, Huang Y. Levels of stigma among community mental health staff in Guangzhou China. BMC Psychiatry. 2014;14:231.

9. Mosaku KS, Wallymahmed AH. Attitudes of primary care health workers towards mental health patients: a cross-sectional study in Osun State Nigeria. Community Ment Health J. 2017;53:176-82.

10. Rojas-Vistorte AO, Silva-Ribeiro W, Jaen D, Jorge MR, Evans-Lacko S, de Jesus Mari J. Stigmatizing attitudes of primary care professionals towards people with mental disorders: a systematic review. Int J Psychiatry Med. 2018;53(4):317-38.

11. Caplan S, Little TV, Garces-King J. Stigma about mental illness among multidisciplinary health care providers in the Dominican Republic. Perspect Psychol Sci. 2016;5(3):192-206.

12. Hori H, Richards M, Kawamoto $Y$, Kunugi $H$. Attitudes toward schizophrenia in the general population, psychiatric staff, physicians, and psychiatrists: a web-based survey in Japan. Psychiatr Res. 2011;186(2-3):183-9.

13. Mittal D, Corrigan P, Sherman M, Chekuri L, Han X, Reaves C, et al. Healthcare providers' attitudes toward persons with schizophrenia. Psychiatr Rehabil J. 2014;37(4):297-303.

14. Smith JD, Mittal D, Chekuri L, Han X, Sullivan G. A Comparison of provider attitudes toward serious mental illness across different health care Disciplines. Stigma and Health. 2017;2(4):327-37.

15. Corrigan PW, Mittal D, Reaves CM, Haynes TF, Han X, Morris S, et al. Mental health stigma and primary health care decisions. Psychiatr Res. 2014:218(1-2):35-8

16. Cabassa LJ, Gomes AP, Meyreles Q, Capitelli L, Younge R, Dragatsi D, et al. Primary health care experiences of hispanics with serious mental illness: a mixed-methods study. Adm Policy Men Health. 2014;41:724-36.

17. Bagayogo IP, Turcios-Wiswe K, Kanako T, Peccoralo L, Katz CL. Providing mental health services in the primary care setting: the experiences and perceptions of general practitioners at a New York City clinic. Psychiatr Q. 2018;89:1-12.

18. Temmingh HS, Oosthuizen pp. Pathways to care and treatment delays in first and multi episode psychosis. Soc Psychiatry Psychiatr Epidemiol. 2008;2008(43):727-35.

19. Tosh G, Clifton A, Bachner M. General physical health advice for people with serious mental illness. Schizophr Bull. 2011;37(4):671-3.

20. Smith DJ, Langan J, McLean G, Guthrie B, Mercer SW. Schizophrenia is associated with excess multiple physical-health comorbidities but low levels of recorded cardiovascular disease in primary care: cross-sectional study. BMJ Open. 2013;3(4):e002808.

21. Küstner BM, Aragón AB, Sepúlveda MJ. Psychometrics properties of a questionnaire on the attitudes of general practitioners to-wards mental health (MAPSAM-14). Anales de Psicología. 2018;34(2):258-63.

22. Lam TP, Lam KF, Lam EWW, Ku YS. Attitudes of primary care physicians towards patients with mental illness in Hong Kong. Asia Pac Psychiatry. 2012:5:E19-E28.

23. Martínez-Zambrano F, García-Morales E, García-Franco M, Miguel J, Villellas $R$, Pascual G, et al. Intervention for reducing stigma: assessing the influence of gender and knowledge. World J Psychiatry. 2013;3(2):18-24.

24. Saeidi S, Wall R. The case for mental health support at a primary care level. Int J Integr Care. 2018;26(2):130-9

25. Morera-Llorcaa M, Romeu-Climentb JE, Lera-Calatayudb G, Folch-Marína B, Vicente Palop-Larreac V, Vidal-Rubiob S. Experiencia de colaboración entre atención primaria y salud mental en el Departamento de Salud La Ribera, 7 años después. Gac Sanit. 2014;28(5):405-7.

26. Reilly S, Planner C, Hann M, Reeves D, Nazareth I, Lester $H$. The role of primary care in service provision for people with severe mental illness in the United Kingdom. PLOS ONE. 2012;7(5):e36468.

27. Vickers KS, Ridgeway JL, Hathaway JC, Egginton JS, Kaderlik AB, Katzelnick DJ. Integration of mental health resources in a primary care setting leads to increased provider satisfaction and patient access. Gen Hosp Psychiatry. 2013;35(5):461-7

28. Ruud T, Aarre TF, Boeskov B, Husevåg PS, Klepp R, Synnøve Alet Kristiansen SA, et al. Satisfaction with primary care and mental health care among individuals with severe mental illness in a rural area: a seven-year follow-up study of a clinical cohort. Int J Ment Health Syst. 2016;10:33. 